\title{
Sloppy Identity, Binding, and Centering
}

\author{
Daniel Hardt \\ Copenhagen Business School
}

\section{Introduction}

The phenomenon of sloppy identity poses a puzzle of sameness and difference in the resolution of ellipsis and other anaphoric forms in discourse. Consider example (1), with the elided VP in parentheses:

(1) John 1 loves his 1 cat. Bill 2 does too. (loves his 2 cat)

A natural requirement is that an elided VP have the same meaning as its antecedent - but on the sloppy reading of (1), the elided VP is interpreted "loves Bill's cat", while the antecedent is "loves John's cat". The most influential solution to this problem invokes variable binding (Keenan 1971, Sag 1976), so that (1) receives the following analysis:

$$
\mathrm{John}_{1} \lambda \mathrm{x} . \mathrm{x} \text { loves x's cat. Bill } 2 \lambda \mathrm{x} . \mathrm{x} \text { loves x's cat }
$$

The variable binding account seeks to solve the puzzle by providing an abstract perspective from which the two VP's may be viewed as identical; in example (1), both antecedent and elided VP receive the interpretation "loves one's own cat". The appeal of this solution is that the abstract perspective posited here has independent motivation; in a compositional semantics, the VP is naturally represented as a lambda abstract, denoting a function which is applied to the subject. The switching observed in sloppy identity is simply the result of applying a lambda abstract to two different arguments. According to this view, sloppy identity should only arise in a very specific configuration: the controller (John in this case) must be a sister to the lambda abstract in which the sloppy variable is bound. I'll call this the locality restriction on sloppy identity.

Although the variable binding analysis of sloppy identity is still considered by many to be the "standard in the semantic literature" (Schwarz 2000), clear evidence against the locality restriction began accumulating some two decades ago, in works such as (Lappin 1984, Evans 1988, Wescoat 1989). Consider the following example:

(3) The police officer who arrested $\mathrm{John}_{1}$ insulted him 1 , and the one who arrested Bill 2 did too. (insulted him ${ }_{2}$ )

(Wescoat 1989)

Here, the sloppy pronoun "him" shifts from John to Bill. This clearly violates locality; the controller John is not sister to the VP containing the sloppy pronoun. 
There are various responses to this in the literature. First, one might simply give up the intuition that an elided expression must be semantically identical to its antecedent, and then attempt to develop a syntactic theory of how exactly an elided expression might differ from the antecedent. This is done by (Fiengo and May 1994), who posit a mechanism of vehicle change to accomplish certain changes from antecedent to ellipsis, together with Dependency Theory, which regulates interpretive changes that arise in sloppy identity. The resulting theory is somewhat less appealing than the variable binding account, since one loses the intuitive appeal of a semantic identity condition, and the proposed mechanisms lack the simplicity and independent motivation of variable binding.

An alternative response is to argue that, despite appearances, variable binding does indeed account for sloppy identity. (Tomioka 1999) argues that problematic cases of sloppy identity involve E-Type pronouns - implicit definite descriptions. Once these implicit descriptions are fleshed out, Tomioka argues, the variable binding analysis suffices to account for sloppy readings. While this account must posit complex underlying representations for pronouns, it does make it possible to retain the otherwise appealing perspective of the variable binding account. Furthermore, following influential arguments by Evans (Evans 1977, Evans 1980) and many subsequent writers, one might argue that the E-Type mechanism has independent motivation.

In this paper, I pursue a very different kind of response to the problem, according to which sloppy identity is explained in terms of Centering Theory(Grosz, Joshi and Weinstein 1995). According to this view, which has been developed in a series of papers, (Hardt 1996, Stone and Hardt 1997, Hardt 1999), a sloppy pronoun can shift its interpretation because it refers to the discourse Center, which is the most prominent entity currently under discussion. As in the variable binding account, the Centering account makes it possible to retain an identity condition on ellipsis and anaphora, since it provides an abstract perspective from which identity can be seen to persist under sloppy readings. Since the centering account makes no direct use of syntactic configurational notions such as sisterhood, it avoids the locality problem.

In this paper I show that the Centering theory of sloppy identity has a striking additional benefit - it provides a uniform solution to two important problems in the interpretation of pronouns: the widely discussed two-pronoun puzzle in ellipsis (see e.g. (Fox 2000)), and a newly discovered problem due to (Percus and Sauerland 2003) involving attitude reports with two pronouns, which I will call the two-pronoun attitude puzzle.

In what follows, I first review the problems for the variable binding account of sloppy identity. Next, I review the centering approach to sloppy identity, as described in previous work. I then turn to the two-pronoun ellipsis puzzle, and show how centering solves the puzzle. Next, I examine the two-pronoun attitude puzzle, and I argue that this is in fact the same puzzle as the two-pronoun ellipsis puzzle, and I show that it receives essentially the same solution. Finally, I examine Tomioka's E-Type account of sloppy identity. I angue that it applies the E-Type mechanism in a way that conflicts with Evans' original intentions, and that in fact 
the proposal is not a viable account of sloppy identity. In fact, I suggest that the proposed centering account can be seen as a way of fleshing out Evans' intended mechanism.

\section{Sloppy Identity: Problems for Variable Binding}

The variable binding account places a strong locality constraint on sloppy identity: it requires sloppy pronouns to be bound in a lambda expression which is a sister to the controller. Only in this case can they be represented as lambda bound variables which can shift their interpretation under ellipsis. This is because the lambda abstract in which the sloppy pronoun is bound is a function whose immediate argument is the controller. The following is an abstract characterization of sloppy identity:

(4) Generalized Sloppy Identity:

$$
\begin{aligned}
& \mathrm{C} 1 \ldots[X P \ldots[Y P] \ldots] \ldots \mathrm{C} 2 \ldots\left[X P^{\prime}\right] \\
& (\mathrm{C} 1, \mathrm{C} 2: \text { "controllers" of sloppy variable } Y P)
\end{aligned}
$$

Generalized Sloppy Identity describes a configuration with an anaphoric expression $X P^{\prime}$, whose antecedent $X P$ contains another anaphoric expression $Y P$. This embedded anaphoric expression $Y P$ can receive a sloppy interpretation, in which it switches from controller $C 1$ to controller $C 2$. Applied to example (1), $C 1$ and $C 2$ are John and Bill respectively; XP is the VP antecedent "loves his cat", and $Y P$ is the sloppy pronoun "his".

The variable binding account requires that $C 1$ and $C 2$ are sisters of $X P$ and $X P^{\prime}$ respectively. As a consequence of this, the two occurrences of the sloppy pronoun $Y P$ must be c-commanded by the controllers $C 1$ and $C 2$. In what follows I review some of the evidence against this locality requirement.

The most widely studied example of sloppy identity involves VPE with a sloppy pronoun. Below are two representative counterexamples to locality in VPE: example (3), repeated below as (5), and (6), from (Hardt 1992).

(5) The police officer who arrested John insulted him, and the one who arrested Bill did too. (insulted him)

(6) If Tom was having trouble in school, I wouldn't help him. On the other hand, if Harry was having trouble, I guess I would. (help him)

As we have already seen, (5) violates locality, since the controller "John" is not a sister to the antecedent VP containing the sloppy pronoun. Similarly with (6) - the controller "Tom" is not a sister to the antecedent VP "help him". These examples show that locality is not required for sloppy identity in VPE. In fact, sloppy identity arises in a variety of different anaphoric forms. For example, a sloppy VPE can be contained within another VPE, as observed in (Hardt 1994) as well as several subsequent works. Consider the following example: 
When John had to cook, he didn't want to $V P E^{i}$ (cook). When he had to clean, he didn't, either. (want to $V P E^{i}$ (clean))

(Schwarz 2000)

Here, the embedded $V P E^{i}$ is a sloppy variable, switching from $C 1$ "cook" to $C 2$ "clean". As Schwarz observes, such cases violate locality, since the sloppy variable is not c-commanded by the controller.

In previous work, I have suggested that sloppy identity is possible for any instantions of XP and YP, where XP and YP are categories that can participate in anaphoric relations. For example, (Hardt 1999) argues that all four possible combinations of NP and VP are possible. Above, we have seen [VP [NP]] and [VP $[V P]]$. The remaining two alternatives [NP [NP]] and [NP [VP]] are given below:

(8) Smith spent his paycheck. Jones saved it.

(9) When Harry drinks, I always conceal my belief that he shouldn't VPE. When he gambles, I can't conceal it.

(Stone and Hardt 1997) argue that tense and modals participate in anaphoric relations and therefore should participate in sloppy identity. They present examples such as the following in support of this: [VP [Tense]] You [ thought I was crazy]. You probably still do VPE. [Modal [NP]] John would use slides if [ [ he] had to give the presentation]. Bill would just use the chalkboard.

In (10), the PAST ("was") contained in the VP antecedent can receive a sloppy interpretation. It switches from the matrix PAST to a matrix PRESENT. In (11), the pronoun "he" is contained in the Modal antecedent to "would". It switches from "John" to "Bill".

The following example is noted by (Elbourne 2001).

(12) Every police officer who arrested some murderers insulted one (murderer), and every police office who arrested some burglars did too. (insulted one (burglar))

This also fits the Generalized Sloppy Identity configuration, with the form [VP [Nbar]]. C1 and $C 2$ are "some murderers" and "some burglars" respectively, with the sloppy variable $Y P$ is the Nbar variable associated with "one". Note again that locality is violated; the sloppy variable YP is not c-commanded by the controller.

Based on this evidence, we conclude that the locality requirement on sloppy identity must be removed; no structural constraints are placed on $C 1$ and $C 2$. In the next section, a processing constraint is proposed instead: $C 1$ and $C 2$ must participate in a center shift, and $Y P$ must refer to the center. 


\section{Sloppy Identity as Center Shift}

According to the centering account of sloppy identity (Hardt 1996, Stone and Hardt 1997, Hardt 1999), the fundamental constraint on sloppy identity is that there must be a center shift between controllers $C 1$ and $C 2$. Furthermore, the sloppy variable $Y P$ must refer to the center. This provides a alternative to the variable binding account of sloppy identity. Like variable binding, it gives a way in which a simple identity condition can be retained. This is not a stipulation to account for sloppy identity, but rather is a consequence of the following general features of the system:

1. A center shift is modeled as reassignment of a distinguished position in the assignment function

2. No other position may be reassigned

3. Ellipsis and anaphora resolution requires identity of indices

We use * to indicate the center, which is position 0 in in the assignment function, or state, of a dynamic semantic system. We use superscript * to indicate that an expression's denotation becomes the new value for the center, and subscript * indicates a reference to the current center. Note that the value of the center is also the value of some ordinary position in the assignment function. So, for example, $\mathrm{John}^{1 *}$ causes John to become the value of both 0 and 1 in the assignment function.

To illustrate, let us consider again example (3), repeated her. Here, the pronouns refer to the center, and the NP Bill causes a center shift from John to Bill.

(13) The police officer 1 who arrested John ${ }^{2 *}[\text { insulted him. }]^{4}$, and the one 5 who arrested Bill ${ }^{3 *}$ did $_{4}$ too. (insulted him ${ }_{*}$ )

The sloppy reading arises because the antecedent VP contains a reference to the center ( him $_{*}$ ), and the intervening context causes a center shift from John to Bill. In this system, VP-meanings are stored as the values of newly introduced discourse markers, which can be accessed by VPE occurrences, which are also represented as discourse markers. We get the following representation for the first sentence:

$$
\begin{aligned}
& {\left[\mathrm{u}_{0}, \mathrm{u}_{1}, \mathrm{u}_{2}, \mathrm{P}_{4} \mid \text { policeofficer }\left(\mathrm{u}_{1}\right), j \operatorname{john}\left(\mathrm{u}_{2}\right), \mathrm{u}_{1}=\mathrm{u}_{0}, \operatorname{arrest}\left(\mathrm{u}_{1}, \mathrm{u}_{0}\right), \mathrm{P}_{4}=\right.} \\
& \left.\lambda \text { u. }\left[\mid \operatorname{insult}\left(\mathrm{u}, \mathrm{u}_{0}\right)\right]\right] ; \mathrm{P}_{4}\left(\mathrm{u}_{1}\right)
\end{aligned}
$$

The VP discourse marker $\mathrm{P}_{4}$ gets the value $\lambda$ u.[l insult( $\left.\left(\mathrm{u}, \mathrm{u}_{0}\right)\right]$, which is the dynamic property of "insulting the current center". This is then applied to $u_{1}$, the discourse marker whose value is "the police officer who arrested John". We continue with the second sentence, arriving at the following representation:

$$
\left[u_{0}, u_{3}, u_{5} \mid \operatorname{onc}\left(u_{5}\right), \operatorname{bill}\left(u_{3}\right), u_{3}=u_{0} \text {, arrest }\left(u_{5}, u_{3}\right)\right] ; P_{4}\left(u_{5}\right)
$$

Here, we have $\boldsymbol{P}_{\mathbf{4}}$ applied to $\mathrm{u}_{5}$, the police officer who arrested Bill. Applying lambda reduction, we get this: 


$$
\left[u_{0}, u_{3}, u_{5} \mid \operatorname{one}\left(u_{5}\right), \operatorname{bill}\left(u_{3}\right), u_{3}=u_{0}, \operatorname{arrest}\left(u_{5}, u_{3}\right), \operatorname{insult}\left(u_{5}, u_{0}\right)\right]
$$

Since the current center is now Bill, this gives the desired sloppy reading, in which the police office insulted Bill.

In what follows, I will focus on cases of VPE with sloppy pronouns. However, it is worth noting that the approach captures quite directly the data given in Section 2, since it instantiates the Generalized Sloppy Identity configuration, and avoids the configurational locality constraint of variable binding. As detailed in previous work, the Centering account of sloppy identity posits discourse referents of any type $a$, where $a$ is the type of a category that can participate in anaphoric relations. Above, we saw examples of anaphora involving nominal, verbal, temporal, and modal types. The Centering account permits a centered discourse referent for each type $a$ as well. ${ }^{1}$ This ensures that a sloppy reading is permitted whenever the Generalized Sloppy Identity configuration is satisfied.

\section{Preferences and Constraints from Centering Theory}

Centering theory models attentional aspects of discourse processing, positing a center, which "represents the discourse entity that [an] utterance ... most centrally concerns, similar to what is elsewhere called the 'topic' "(Walker, Prince and Joshi 1998). The center shifts periodically throughout the discourse, and centering theory investigates constraints and preferences on the management of the center, involving factors such as structural prominence, discourse coherence, and ease of processing.

The centering literature contains a variety of proposals for constraining the establishment and shifting of the center, encompassing a broad range of factors, including syntactic prominence, intonation and pragmatics. In general, there is believed to be a preference for the NP establishing the center to occupy subject position, or to otherwise be syntactically prominent. However, there is no requirement analogous to the locality requirement of variable binding; a pronoun can refer to the center regardless of the particular structural relationship between the pronoun and the NP that established the center.

Here, I propose two ways in which centering and pronoun indexing interact:

- Centering Requirement: If the value of the center is the value of index $i$, pronouns may not be indexed with $i$.

Recall that the value of the center is always the value of an ordinary index as well. The Centering Requirement makes this ordinary index temporarily unusable. The idea is that the center is in some sense an easier memory location to access, and one psychological function of centering is to simplify processing by taking advantage of this ease of access, for an entity that is accessed repeatedly. The Centering Requirement merely ensures that pronoun indexing takes advantage of this benefit.

- Centering Preference: A pronoun $\mathrm{p}_{*}$ is preferred over $\mathrm{p}_{i}$ for any non-zero $i$. 
- The Centering Preference is overridden by contra-indexing constraints and agreement constraints, and may be overridden by other factors such as plausibility.

According to the Centering Preference, a reading is preferred in which a pronoun refers to the center, unless other factors intervene. ${ }^{2}$

\section{The Two-Pronoun Ellipsis Puzade}

Consider now the ellipsis 2-pronoun puzzle, first noted by (Dahl 1973), and discussed extensively in subsequent literature.

(17) John said he saw his mother. Bill did too (said he saw his mother).

Assume the first sentence is interpreted "John said John saw John's mother". Since both of the pronouns he and him can be strict or sloppy, there are four potential readings for the second sentence:

1. Bill said John saw John's mother.

2. Bill said Bill saw Bill's mother.

3. Bill said Bill saw John's mother.

4. *Bill said John saw Bill's mother.

While all four readings are permitted by the variable binding account, in fact the 4th reading is generally agreed to be degraded or impossible. Many prominent accounts (eg. (Fiengo and May 1994, Fox 2000)) agree that the relevant generalization is this:

\section{A strict pronoun may not c-command a sloppy pronoun}

I will call this the c-command generalization. My explanation for this rests on two key points: first, the centering approach rules out "mixed" readings, since sloppy identity is a result of a center shift from John to Bill. Thus, either there is no center shift, in which case all pronouns must remain strict, or there is a center shift, and all pronouns are sloppy. The second key point is that Reading 3 can be represented as an unmixed reading, relying on ordinary syntactic movement, while this is not possible for Reading 4 . This second point is simply an observation that holds independently of the centering proposal.

We start with the unproblematic readings 1 and 2:

(19) (Reading 1) John ${ }^{1 *}$ said he saw $\left[\text { his }_{*} \text { mother }\right]_{3}$. Bill ${ }^{2}$ did too. (said

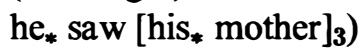


(Reading 2) John ${ }^{1 *}$ said he saw $\left[\text { his } \text { * }_{*} \text { mother }\right]_{3}$. Bill ${ }^{2 *}$ did too. (said he $_{*}$ saw $\left[\text { his }_{*} \text { mother }\right]_{3}$ )

For Reading 1, there is no center shift from John to Bill, so both pronouns in the VPE refer to John. For Reading 2, the center shifts from John to Bill in the second sentence, so the two pronouns in the VPE both refer to Bill.

We now examine Readings 3 and 4 . Both of these readings contain a sloppy pronoun, which means there must be a center shift from John to Bill. However, each reading also contains a non-sloppy pronoun, which we will call the "offending pronoun". In Reading 3, the second pronoun, "his", is the offending pronoun, while in Reading 4, it is the first pronoun, "he". The crucial difference is that, in Reading 3 , the offending pronoun is embedded in a larger NP "his mother", and this larger NP can be raised outside of the VP, by applying QR (May 1985) or, more generally, NP-raising (Heim 1982). Thus we adjoin "his mother" to the matrix VP, leaving a coindexed trace:

(21) John ${ }^{1 *}\left[\left[\text { his }_{*} \text { mother }\right]_{3}\left[\right.\right.$ said he ${ }_{*}$ saw $\left.\left.e_{3}\right]\right]$, Bill ${ }^{2 *}$ did too (said he saw $\left.e_{3}\right)$.

With this representation, Reading 3 is permitted - the center shift causes "he" to be interpreted as "Bill", and $e_{3}$ is interpreted as John's mother. The definite description "his mother 3 " sets up John's mother as the value of 3 in the assignment function, which is made available for the variable $e_{3}$ in the following sentence, as shown below:

$$
\begin{aligned}
& {\left[u_{0}, u_{1}, u_{3}, P_{4} \mid \operatorname{John}\left(u_{1}\right), u_{1}=u_{0}, \text { mother-of }\left(u_{3}, u_{0}\right), P_{4}=\lambda u .[\operatorname{said}(u,\right.} \\
& \left.\left.\operatorname{saw}\left(u_{0}, u_{3}\right)\right]\right] ; P_{4}\left(u_{0}\right) \\
& {\left[u_{0}, u_{2} \mid \operatorname{Bill}\left(u_{2}\right), u_{2}=u_{0}\right] ; P_{4}\left(u_{0}\right)}
\end{aligned}
$$

The representation for the second sentence, $P_{\mathbf{4}}\left(u_{0}\right)$, is equivalent to:

$$
\text { [ } \operatorname{said}\left(u_{0}, \operatorname{saw}\left(u_{0}, u_{3}\right)\right]
$$

Since the current value of $u_{0}$ is Bill, and the current value of $u_{3}$ is John's mother, this gives the reading "Bill said Bill saw John's mother", as desired.

There is no way to represent Reading 4 in an unmixed way. This is because in Reading 4, the offending pronoun "he" c-commands the sloppy pronoun "him". Thus there is no constituent containing "he" which does not also contain the other pronoun "him". So we cannot move "he" out to produce an unmixed representation for Reading 4. The only possibility is to raise "he *", but this would have no effect, since the trace $\mathrm{e}_{*}$ would remain:

(24) $\mathrm{John}^{1 *}\left[\mathrm{he}_{*}\right.$ [said $\mathrm{e}_{*}$ saw [his mother] $\left.]\right]$, Bill $^{2 *}$ did too (said $\mathrm{e}_{*}$ saw

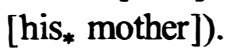


The crucial point here is that Reading 3, but not Reading 4, can be represented as unmixed. I have shown this using NP-raising, a syntactic movement operation, but the point could be made without recourse to syntactic movement. It is uncontroversial that an NP appearing under an intensional verb can have its interpretation fixed outside the intensional context, as in the following example:

(25) John thought the murderer was a woman.

Here, "the murderer" can be interpreted as some individual $x$ independently of John's thoughts, giving the interpretation the [x:murderer] John thought $\mathrm{x}$ was a woman. (Neale 1990). Whatever mechanism produces this sort of de re reading would presumably suffice to give Reading 3 an unmixed representation.

While this raising mechanism is typically restricted to NP's (as in (Heim 1982)) or quantified NP's (as in (May 1985)), I propose to allow any constituent to move out of an intensional context and have its interpretation fixed. This is necessary to fully capture the two-pronoun c-command constraint, as illustrated by the following variant:

$$
\text { John said his mother saw him. Bill did too. }
$$

Here there is no c-command between the two pronouns; as observed by (Fiengo and May 1994), all four readings are possible here.

1. Bill said John's mother saw John.

2. Bill said Bill's mother saw Bill.

3. Bill said John's mother saw Bill.

4. Bill said Bill's mother saw John.

Reading 3 can be derived by raising "his mother".

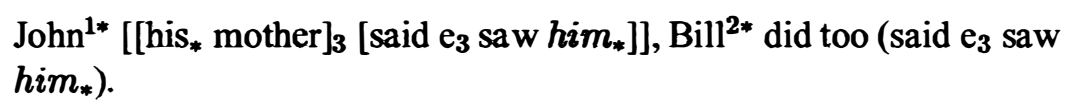

To derive Reading 4, we need to move a constituent containing "him" that does not contain "his". We move the VP "saw him".

(28) John ${ }^{1 *}\left[[\text { saw him }]_{4}\right.$ [said $\left[\right.$ his mother $_{3}$ did $\left.\left.\mathrm{P}_{4}\right]\right]$ Bill ${ }^{2 *}$ did too [said [his mother $_{3}$ did $\mathrm{P}_{4}$ ]]

Crucially, the type of $\mathrm{P}_{4}$ is $\langle e, t\rangle$, a static property, whose value is "saw John". This correctly derives the reading "Bill said Bill's mother saw John".

Space does not permit a thorough consideration of the extensive literature on the two-pronoun ellipsis puzzle. I confine myself to a brief consideration of the account of (Fox 2000). This account combines two elements: a parallelism constraint on sloppy pronouns, and an economy requirement for selecting the shortest possible binding link. Consider Reading 4: 
$\mathrm{John}_{1}$ said he $_{1}$ saw his mother. $_{1}$

Bill $_{2}$ did too (said he 1 saw his 2 mother).

Because of the shortest link requirement, his ${ }_{1}$ must be linked to he ${ }_{1}$ in the first sentence (rather than to John ${ }_{1}$ ). In the second sentence, his ${ }_{2}$ must be linked to Bill $_{2}$; thus it has a different link than that of the corresponding his $\mathbf{s}_{1}$ in the antecedent, violating parallelism. Reading 3 is permitted, because the sloppy pronoun $\mathrm{he}_{2}$ is linked to Bill 2 , satisfying parallelism.

(30) John said he $_{1}$ saw his 1 mother.

Bill $_{2}$ did too (said he ${ }_{2}$ saw his 1 mother).

Fox's account captures the c-command generalization: a strict pronoun may not c-command a sloppy pronoun. The account of (Fiengo and May 1994) captures the same generalization, although it relies on very different machinery. Both Fox's and Fiengo and May's accounts rely on a parallelism constraint, which involves comparing two structures (such as antecedent VP and VPE). As we will see below, a similar effect arises in the two-pronoun attitude puzzle, which involves only a single structure. Because of this, these accounts cannot capture the attitude puzzle.

The centering account also captures the c-command generalization: a mixed reading can be given an unmixed representation by moving a constituent which contains the strict pronoun but doesn't contain the sloppy pronoun. This cannot be done if the strict pronoun c-commands the sloppy pronoun, since then every constituent containing the strict pronoun also contains the sloppy pronoun. Unlike other accounts, the centering account applies directly to the attitude puzzle.

\section{The Two-Pronoun Attitude Puzzle}

We turn now to the attitude puzzle (Percus and Sauerland 2003), involving sentences of the following form:

(31) John dreamed that he was marrying his grand-daughter.

As explained at length by Percus and Sauerland, the puzzle arises when (31) describes a situation in which John believes, in his dream, that he is Bill. Just as in the two-pronoun ellipsis puzzle, we have two pronouns (he and his), both of which have two choices, John and Bill. (Other possibilities are not of interest here.) We have four potential readings:

1. John dreamed that John was marrying John's grand-daughter.

2. John dreamed that Bill was marrying Bill's grand-daughter.

3. John dreamed that Bill was marrying John's grand-daughter.

4. * John dreamed that John was marrying Bill's grand-daughter. 
As Percus and Sauerland point out, one apparently mixed reading is possible while the other is not - (31) can mean "John dreamed Bill was marrying John's grand-daughter", but not "John dreamed John was marrying Bill's grand-daughter".

The centering account provides an immediate explanation: just as in the ellipsis puzzle, the offending pronoun "his" can be removed by NP-raising, thus allowing an unmixed representation for Reading 3. The only additional assumption required is that "dream" can optionally cause a center shift, so that the center under the scope of "dream" can shift to Bill. (Note that the account in (Percus and Sauerland 2003) requires an analogous assumption: propositional verbs like "dream" introduce a set of individual-world pairs $\langle y, w\rangle$ where $y$ is a representation of "self" in $w$.)

Let us begin with the unproblematic readings 1 and 2 :

$$
\begin{aligned}
& \text { (Reading 1) John }{ }^{1 *} \text { dreamed he } \\
& \text { (Reading 2) } \mathrm{John}^{1 *} \text { dreamed }^{\text {Bill }^{* *}} \text { he } \\
& \text { * was marrying }\left[\text { his }_{*} \text { granddaughter }\right]_{3}
\end{aligned}
$$

For Reading 1, there is no center shift from John to Bill, so both pronouns refer to John. For Reading 2, dream shifts the center from John to Bill, so the two pronouns both refer to Bill. Let us now consider Reading 3. Here we have "his granddaughter" VP-adjoined, as a result of NP-raising:

$$
\text { John }^{1 *}\left[\text { his }_{*} \text { granddaughter }\right]_{3} \text { dreamed }^{\text {Bill }{ }^{* *}} \text { he } \mathrm{e}_{*} \text { was marrying } \mathrm{x}_{3}
$$

Just as in the two-pronoun ellipsis puzzle, NP-raising produces a representation which is unmixed - the offending pronoun "his" is moved to a position before the center shift. Reading 4 is ruled out here for the same reason as in the VPE case: for Reading 4, this can't be done, since the offending pronoun "he" c-commands the other pronoun, "his". Thus any constituent containing "he" also contains "his".

Note that both pronouns have been indexed with *. This follows the Centering Preference, since this indexing violates no other relevant preference factors or constraints, we predict that readings requiring other indexing should be degraded. The Centering Preference plays a key role in ruling out Reading 4. With the following indexing, which violates the Centering Preference, we can capture Reading 4.

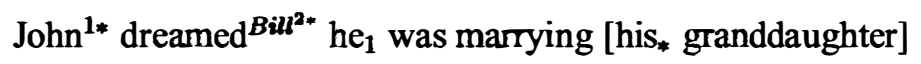

Here "he" refers to "John" rather than to the center. Since this representation violates the Centering Preference, this suggests that Reading 4 is possible here, but that there is a preference for Readings 1-3. For the two-pronoun ellipis puzzle, Reading 4 cannot be represented by violating the Centering Preference; it can only be represented by violating the Centering Requirement. This suggests that there should be a difference in relative acceptability in the two cases, although this difference is perhaps difficult to perceive.

The account in (Percus and Sauerland 2003) captures the following generalization: a SELF-pronoun cannot be c-commanded by a non-SELF pronoun. In 
Reading 4, the pronoun referring to Bill is a SELF-pronoun, since it refers to John's representation of SELF in the dream context. Since the non-SELF pronoun "he" c-commands the SELF pronoun "his" in Reading 4, it is ruled out. In Reading 3, the SELF pronoun c-commands a non-self pronoun. This is permitted. Consider the two cases of the two-pronoun puzzle:

- Ellipsis Case (Fox/Fiengo and May): Strict pronoun may not c-command sloppy pronoun

- Attitude Case (Percus and Sauerland 2003): Non-SELF pronoun may not c-command SELF pronoun

The centering account is able to capture both cases under a single generalization:

- Non-centered pronoun may not c-command centered pronoun

This is not stipulated, but follows from general features of the system, combined with completely standard possibilities for movement. As we have seen, the non-centered pronoun can be separated from a centered pronoun by movement, as long as c-command does not hold.

\section{E-Type Account of Sloppy Identity: Critique}

In this section I consider an alternative proposal for solving the problems in the variable binding approach to sloppy identity. (Tomioka 1999) proposes that unbound sloppy pronouns are E-Type pronouns. In example (3), the pronoun "him" is represented by the definite description the $x$ that he $e_{1}$ arrested, as shown here:

(36) The police officer 1 who arrested $\mathrm{John}_{2}$ insulted the $x$ that he $e_{1}$ arrested, and the one $e_{3}$ who arrested Bill 4 did too. [insulted (the $x$ that he 3 arrested)]

This is equivalent to the desired reading, in which the antecedent VP means insulted John and the elided VP means insulted Bill. With the more complex representation, there is no longer a problem for the variable binding approach - now, the sloppy pronoun is $h e_{1}$, which is c-commanded by its controller, namely the matrix subject.

An essential ingredient in this account is the view that pronouns can optionally be viewed as implicit definite descriptions, where the content of the definite description is recovered from context. This is a widely held view, expressed for example in this textbook (Heim and Kratzer 1998, page 288):

E-Type pronouns can always be paraphrased by certain definite descriptions. 
Before looking in more detail at the application of the E-Type analysis to sloppy identity, I wish to point out some problems with this underlying assumption. Surprisingly, this view is in fact at odds with Evans' original view (Evans 1977). In the paper introducing the E-Type analysis, Evans argues at length that a description should not appear in place of an E-type pronoun.

...the sentence which results when the description takes the place of the E-type pronoun (the 'prolix sentence') is often ambiguous in a way in which the original sentence is not. The trouble arises because definite descriptions give rise to scope ambiguities when interacting with almost all operators [page 132].

Evans gives the following series of examples to illustrate this point. These examples involve interaction with modality, time and psychological attitudes.

(37) John owns a donkey and it likes carrots, though it might not have been the case that it likes carrots.

(38) John owns a donkey and it likes carrots, though it might not have been the case that the donkey John owns likes carrots.

(39) Boston has a Mayor and he used to be a Democrat.

(40) Boston has a Mayor and the Mayor of Boston used to be a Democrat.

(41) A man murdered Smith, but John does not believe that he murdered Smith.

(42) A man murdered Smith, but John does not believe that the man who murdered Smith murdered Smith.

Take, for example, (39) and (40). Evans claims that (39) is unambiguous he must refer to the current mayor of Boston. But he finds (40) to be ambiguous; the Mayor of Boston might refer to the current mayor, who was a Democrat in the past, or it might refer to a previous mayor. Evans makes similar points with respect to the other examples.

One might dispute this; (Neale 1990), for example, argues that (39) is indeed ambiguous, and that he could refer to a previous mayor of Boston. However, it seems clear that Evans is right that there is a difference; that the definite description in (40) facilitates this interpretation, which is less prominent in (39).

\subsection{Interaction with Ellipsis}

A similar effect can be observed in the interaction between hidden descriptions and ellipsis resolution, as shown by the contrast between (43) and (44)(Hardt 2001).

(43) The patrolman ${ }_{1}$ who arrested a burglar 2 interrogated him 2 . Detective Wilson $_{3}$ did too. (interrogated him ) $^{2}$ 
(44) The patrolman 1 who arrested a burglar ${ }_{2}$ interrogated the burglar he arrested. Detective Wilson 3 did too. (interrogated the burglar he arrested)

(44) has a sloppy reading, in which Detective Wilson interrogated a different burglar. Example (43) lacks a sloppy reading: the only reading is the strict one, according to which Detective Wilson interrogated the same burglar as the patrolman. This is not surprising: in (44) the antecedent VP contains a pronoun him that can switch from the patrolman to Detective Wilson. In (43), there is simply no such pronoun. But according to the E-Type account, (43) should have the same representation as (44), which means it should have exactly the same sloppy reading as observed in (44).

These ellipsis support Evans' original claim, perhaps more strikingly than his own examples: definite descriptions interact with context in a way that simple pronouns do not. This poses a fundamental problem for any account that would assimilate pronouns to definite descriptions.

\subsection{Fixing E-Type: Shrinking the Definite Description}

(Elbourne 2001) and (Büring 2001), in response to the above problem of spurious sloppy readings, suggest that a smaller definite description can solve the problem. So far, I have been following the proposal in (Heim 1990), in which the definite description is constructed from the entire $S$ containing the antecedent NP.

(Elbourne 2001) proposes that the description is constructed from just the antecedent NP itself. This means that for example (43), we would now have this:

The patrolman ${ }_{1}$ who arrested a burglar 2 interrogated the burglar. Detective Wilson $_{3}$ did too. (interrogated the burglar)

This removes the spurious sloppy reading, because the problematic pronoun was not within the antecedent NP, but rather, was in the surrounding S. However, this does not solve the problem in general. In the following example, the problematic pronoun is placed within the antecedent NP, and the spurious sloppy reading resurfaces.

(46) When Officer Smith saw the burglar he arrested, he interrogated him. Detective Jones did too.

When Officer Smith saw the burglar he arrested, he interrogated the burglar he arrested. Detective Jones did too.

A further proposal for reducing the copied definite description can be found in (Chierchia 1992). Here, the proposal is that just the N-head of antecedent NP is copied. This does solve the spurious sloppy reading. However, it is subject to a different problem, illustrated by the following contrast: 
(48) The police officer who arrested a burglar insulted him, and the one who arrested a murderer did too.

(49) The police officer who arrested a burglar insulted the burglar, and the one who arrested a murderer did too.

(Tomioka 1999)

Here, the E-type approach incorrectly rules out the sloppy reading, because burglar must be part of the descriptive content of the E-type pronoun him, which is in turn copied by VPE resolution.

We have seen substantial evidence in support of Evans' contention that Etype pronouns must not be represented as hidden definite descriptions. Evans' original proposal was that the antecedent fixes the referent for the subsequent unbound pronoun. The current proposal can be seen as giving an explicit mechanism for this, in the context of a dynamic model involving centering.

\section{Two-pronoun Cases Without Locality}

Here we examine the combination of two factors that have figured prominently in this paper: sloppy identity without locality, and multiple sloppy pronouns. As far as I know, it has not been previously observed that two-pronoun cases are possible with a non-local controller, as in the following example:

(50) The police officer who arrested John knew he saw his mother, and the one who arrested Bill did too.

For the Centering account, we have the same result as for the original VPE 2-pronoun example; the lack of locality plays no role. We have the following indexings for Readings 1 and 2:

(51) (Reading 1) The police officer who arrested John ${ }^{1 *}$ knew he saw [his H $_{*}$ mother $]_{3}$. The one who arrested Bill ${ }^{2}$ did too. (knew he ${ }_{*}$ saw $\left[\right.$ his $_{*}$ mother $]_{3}$ )

(52) (Reading 2) The police officer who arrested John ${ }^{1 *}$ knew he ${ }_{*}$ saw [his mother $]_{3}$. The one who arrested Bill ${ }^{2 *}$ did too. (knew he ${ }_{*}$ saw $\left[\right.$ his $s_{*}$ mother $]_{3}$ )

Reading 3 is derived in the same way, by moving "his mother", and shifting the center.

(53) (Reading 3) The police officer who arrested John ${ }^{1 *}\left[\left[\text { his }_{*} \text { mother }\right]_{3}\right.$ [knew he ${ }_{*}$ saw $\left.e_{3}\right]$. The one who arrested Bill ${ }^{2 *}$ did too (knew he ${ }_{*}$ saw $e_{3}$ ). 
As before, Reading 4 is not possible, because the offending pronoun "he" cannot be moved without moving the other pronoun "his".

For the E-Type approach, the two pronouns can be represented as definite descriptions, since they are not c-commanded by their antecedent, as follows:

(54) The police officer who arrested John knew [the $x$ he arrested] saw [the $\mathrm{x}$ he arrested]'s mother, and the one who arrested Bill did too.

Now the two sloppy pronouns are the two occurrences of "he" embedded in the two definite descriptions. Since they are not related by c-command, the 4th reading will no longer be ruled out by existing accounts, such as that of (Fox 2000).

\section{Conclusions}

While, the variable binding account of sloppy identity is elegant and intuitively appealing, it has long been known to be overly restrictive in terms of locality. In response to this, theorists such as (Fiengo and May 1994) have proposed rather far-reaching complications of the syntax-semantics interface. The present proposal makes it possible to retain a simple syntax-semantics interface, and relies instead on some basic notions concerning the processing of pronouns, imported (and adapted) from Centering theory.

Previous work has shown that the centering account of sloppy identity is more flexible than variable binding, since it avoids the locality restriction built into the variable binding approach. In this paper, I have shown that centering is in some ways more restrictive than variable binding. It provides a direct account of restrictions observed in the two-pronoun ellipsis puzzle and the two-pronoun attitude puzzle. While other authors have provided accounts of one or the other of these two puzzles, no previous account applies to both. The key to a uniform account of these puzzles is the prohibition against mixed readings, which arises naturally in the centering account.

\section{References}

Bittner, M.: 2001, Topical referents for individuals and possibilities, Proceedings from SALT XI.

Büring, D.: 2001, Variable binding out of dp revisited, Proceedings of the Eleventh Conference on Semantics and Linguistic Theory, New York.

Chierchia, G.: 1992, Anaphora and dynamic interpretation, Linguistics and Philosophy.

Dahl, O.: 1973, On so-called 'sloppy identity', Gothenburg Papers in Theoretical Linguistics 11, University of Gothenburg, Sweden. 
Elboume, P.: 2001, E-type anaphora as np-deletion, Natural Language Semantics 9(3), 241-288.

Evans, F.: 1988, Binding into anaphoric verb phrases, Proceedings of ESCOL 1988, pp. 122-129.

Evans, G.: 1977, Pronouns, quantifiers, and relative clauses, Canadian Journal of Philosophy 7, 467-536.

Evans, G.: 1980, Pronouns, Linguistic Inquiry 11, 337-362.

Fiengo, R. and May, R.: 1994, Indices and Identity, MIT Press, Cambridge, MA.

Fox, D.: 2000, Economy and Semantic Interpretation, MIT Press.

Grosz, B., Joshi, A. and Weinstein, S.: 1995, Centering: A framework for modeling the local coherence of a discourse, Computational Linguistics.

Hardt, D.: 1992, A semantic theory of verb phrase ellipsis, Proceedings of the Second Conference on Semantics and Linguistic Theory, Columbus, Ohio.

Hardt, D.: 1994, Sense and reference in dynamic semantics, Proceedings of the Ninth Amsterdam Colloquium.

Hardt, D.: 1996, Centering and dynamic semantics, Proceedings, COLING 96, Copenhagen, Denmark.

Hardt, D.: 1999, Dynamic interpretation of verb phrase ellipsis, Linguistics and Philosophy 22(2), 187-221.

Hardt, D.: 2001, Interpretation of pronouns: Etype vs. drt.

Heim, I.: 1982, The Semantics of Definite and Indefinite Noun Phrases, PhD thesis, University of Massachusetts-Amherst.

Heim, I.: 1990, E-type pronouns and donkey anaphora, Linguistics and Philosophy.

Heim, I. and Kratzer, A.: 1998, Semantics in Generative Grammar, Blackwell, Oxford.

Keenan, E.: 1971, Names, quantifiers, and the sloppy identity problem, Papers in Linguistics 4(2), 211-232.

Lappin, S.: 1984, Vp anaphora, quantifier scope, and logical form, Linguistic Analysis 13(4), 273-315.

May, R.: 1985, Logical Form: Its Structure and Derivation, MIT Press, Cambridge, MA.

Neale, S.: 1990, Descriptions, MIT Press, Cambridge, MA. 
Percus, O. and Sauerland, U.: 2003, On the lfs of attitude reports, Proceedings of Sinn und Bedeutung VII.

Poesio, M., Stevenson, R., Cheng, H., di Eugenio, B. and Hitzeman, J.: 2001, A corpus-based evaluation of centering theory, University of Essex, NLE Technical Note TN-02-01.

Sag, I. A.: 1976, Deletion and Logical Form, PhD thesis, Massachusetts Institute of Technology. (Published 1980 by Garland Publishing, New York).

Schwarz, B.: 2000, Topics in Ellipsis, PhD thesis, University of MassachusettsAmherst.

Stone, M. and Hardt, D.: 1997, Dynamic discourse referents for tense and modals, in $\mathrm{H}$. Bunt, R. Muskens and G. Rentier (eds), Second International Workshop on Computational Semantics, ITK, Tilburg, NL.

Tomioka, S.: 1999, A sloppy identity puzzle, Natural Language Semantics 7, 217241.

Walker, M., Prince, E. and Joshi, A.: 1998, Introduction, in M. Walker, E. Prince and A. Joshi (eds), Centering theory in discourse, Oxford University Press.

Wescoat, M.: 1989, Sloppy readings with embedded antecedents, Stanford University.

\section{Endnotes}

0. Many thanks to Matthew Stone, Maribel Romero, Bernard Schwarz, and Massimo Poesio for useful comments and suggestions.

1. The account in (Bittner 2001) also posits centered entities of a variety of semantic types.

2. While this preference factor as stated is not standard in the Centering literature, it would appear to receive empirical supported from the recent study in (Poesio, Stevenson, Cheng, di Eugenio and Hitzeman 2001), in which it is reported that over $60 \%$ of third person pronouns refer to the center. Further investigation of this issue is required, to determine how the proposed Centering Preference factor interacts with other preference factors and constraints. 